\title{
A replicated two-level total factorial analysis: deformation in aluminum alloy skins caused by riveting processes
}

\author{
Daniella Yada Negroni, Luís Gonzaga Trabasso \\ Aeronautics Institute of Technology \\ e-mails: dynegron@ita.br; gonzaga@ita.br
}

\begin{abstract}
The objective of this work was to demonstrate the following: the deformation effect in aluminum alloy skins when a riveting process is applied; to determine which factors, such as hole diameter, depth of countersunk etc. affect the skin deformation, and the degree of this influence. In order to identify the candidate factors relating to the deformation effect, a survey was carried out with riveting process and material science specialists. The survey results were analyzed and detailed further. Then, an experimental approach was conducted based on the Taguchi Robust Design, which used the factors previously elected, as well as a set of samplings. Finally, a variance analysis, which was based on a multifactor variance method, was performed. Results showed the expansion of the panels after the riveting process, the identification of factors of influence on this expansion, and the suggestion of possible actions to reduce this deformation.
\end{abstract}

Keywords: aircraft assembly, design of experiments, regression model fit.

\section{Introduction}

\subsection{Difficulties of the riveting process in the aeronautical industry}

During the assembly of aircraft fuselages it was observed that after the riveting process, some lateral panels always bear deformation; this change results in a radius reduction of the panel. It is likely that this phenomenon is due to the deformation of the skin, as the skins are relatively large (approximately 5 meters in length) and the riveting lines usually have more than 100 rivets.

\subsection{Hypothetical correlation between skin deformation and the riveting process}

A finite element analysis of the riveting process was carried out (LI; SHI, 2003) and it was detected that when a rivet is installed, the hole suffers a small expansion (due to expansion of the rivet diameter), and the rivet pitch propagates approximately in a ratio of $1 / 10$. Consequently, an expansion of $0.1 \mathrm{~mm}$ in the hole of the skin would increase the rivets pitch around $0.01 \mathrm{~mm}$. A riveting line of 100 rivets would expect to have a $1 \mathrm{~mm}$ increase, which matches approximately with the magnitude of the hypothetical phenomenon mentioned above, regarding large size fuselages. However, this result can not be fully confirmed through computer simulation. Computer aided engineering (CAE) software such Nastran ${ }^{\mathrm{TM}}$, is unable to accurately simulate plastic deformations that occur during the riveting process.

A number of studies as Blanchot and Daidie (2006) simulate the riveting process using a 3-D finite element model. The structural stress analysis performed by Blanchot et al. (2006) presents adjustment of a numerical model simulating a riveted plate that uses different approaches. These are: slice model $\left(15^{\circ}\right.$ sector portion made up of quad elements), axisymmetry model (only one semi-section is considered) and 3D model (symmetrical reduced to one half of the 3D geometry due to the plane of symmetry). According to the results from 3D model, plastic strain does not affect the plates and is non-homogeneous in the rivet.

Another method such as Rans et al. (2007) was used to verify the residual stress field and establish the influence of through-thickness compression on joined sheets during riveting. The results from this research challenge the traditional comparisons between the riveting and radial expansion processes. These usually state that large through-thickness stresses are generated in the joint sheets underneath the rivet head during rivet installation, adding up to plasticity effects within this region.

Other work (JOHNSON, 2006) employs frequency domain data interrogation techniques to identify the areas within fuselage structures, where damage might occur. At 
this study a continuous engineering measurement process Structural Health Monitoring (SHM) - was applied to detect, locate and quantify the structural degradation of materials. Furthermore, prognostic algorithms are used to make life predictions in real time.

These researches are primarily focused on engineering properties, such as fatigue and residual stress, but do not predict the deformation value in the plates. This work demonstrates the plastic deformation of aluminum alloy skins caused by the riveting process based in experimental data and presents the variation of this deformation value when some factors are combined. It aims at improving product quality and increasing process productivity, by avoiding potential reworks during the assembly process.

\section{Experimental procedure}

As the problem to be studied - effect of the deformation in skin aluminum due to the Riveting process - has a great number of variables whose effect on the process is unknown, it is not feasible in practical terms to perform a fully factorial experiment (LOGOTHETIS, 1989). Thus, the experimental procedure was split in two phases, as follows:

Choice of the factors;

Accomplishment of the experiment.

\subsection{Choice of the variables (factors) of the experiment}

A questionnaire and an evaluation matrix were elaborated for choosing the most significant variables according to the experience and technical knowledge of riveting and materials specialists. As a result, eleven variables were chosen that might influence the phenomenon of skin stretching. They are:

1) Countersunk height: In accordance to engineering specifications, the height of the countersunk can vary up to $0.89 \mathrm{~mm}$ for the $5 / 32$ inch hole diameter $(3.96 \mathrm{~mm})$. To aid the measurement task, the height of the countersunk is measured as the height of the rivet in relation to the surface of the sink. The greater the height of the rivet after the riveting, the lesser the height of countersunk.

2) Gap before the riveting process: According to the Aerospace Standard NASM 14219 (AMERICAN..., 1999), the gap between the hole and the rivet before the riveting process (hole diameter minus rivet diameter) is expected to be from $0.09 \mathrm{~mm}$ up to $0.24 \mathrm{~mm}$ for a $5 / 32$ inch diameter hole $(3.96 \mathrm{~mm})$.

3) Load of the stamp machine: The load applied by the stamp machine can be adjusted during the manual and automatic riveting process.

4) Load speed of the stamp machine: The speed applied to the load of stamp machine can be adjusted during the process.
5) Quantity of strokes of the stamp machine per hole: The amount of strokes intervenes with the height of the rivet and with the amount of material that is conformed within the hole. This variable is analyzed only for the manual riveting process.

6) Rivet diameter: It can range from $2.4 \mathrm{~mm}$ to $7.9 \mathrm{~mm}$.

7) Rivet material: The material of the rivet can be either A12117 (70 Rockwell B) or Al7050 (147 Rockwell B); they present different mechanical behavior during the riveting process due to the hardness difference.

8) Rivet type: Two types can be considered - straight line or Brille $\left(120^{\circ}\right)$. Due to its geometry can generate different standards of force (magnitude and direction) on the wall of the hole.

9) Riveting sequence: The riveting sequence, like leftup to right-down, can intervene in the propagation of the deformation, mainly when the panels are fixed in gage points at tooling during the riveting process.

10)Thickness of the skin: The commonly used thickness of skin in the aeronautical industry varies from $1.5 \mathrm{~mm}$ up to $2.0 \mathrm{~mm}$.

11)Riveting process (Manual or Automatic): The manual process is performed in several cycles (or strokes) until the rivet is conformed to accomplish the technical specifications of rivet height and area head. The automatic process is performed in one cycle (stroke).

After choosing the variables above, they were classified in to two types:

1) Product Variable (PtV): They might interfere with the characteristics of the product, being able to modify its functionality.

These are: Rivet material, Rivet type, Rivet diameter and Thickness of the skin.

2) Process Variable of (PsV): They might interfere with the characteristics of the riveting process, being able to modify the effectiveness and efficiency of the process.

These are: Gap before the riveting process, Riveting sequence, Riveting process, Load of the stamp machine, Load speed of the stamp machine, Countersunk height and Quantity of strokes of stamp machine per hole.

The variables Rivet type and Rivet diameter, by consensus of the specialists, are specified to attend aeronautical functionalities such as aerodynamics and fatigue endurance. Therefore, they were considered as preconditions for the experiment, being set as follows:

- Rivet type: Brille $\left(120^{\circ}\right)$ - it is more frequently used in aeronautical industries due to its strong sealing characteristics.

- Rivet diameter: the $5 / 32$ inch $(4.0 \mathrm{~mm})$ diameter is more frequently used in the aeronautical industry. 
The variables Load of the stamp machine and Load speed of the stamp machine were considered as derived from the variable Riveting process because these are the chief characteristics that differentiate the riveting processes. If a complementary analysis of the variable Riveting process is found necessary, then the two variables may be further analyzed.

Each respondent (process and/or materials specialist) attributed a weight to each variable according to his/her knowledge about the potential influence the variable might have upon the skin deformation phenomenon. The four-level criterion was presented to the respondents: (1) Irrelevant, (2) Little Relevance, (4) Relevant and (8) Very Relevant. The results gathered from this survey are shown in Table 1.

The final evaluation score for each variable was calculated through the product of the individual evaluations, divided by a factor of 1000 to normalize the comparison between the numbers obtained, according to Equation 1.

$$
\mathrm{Px}=\left(\prod_{i=1}^{\mathrm{n}} \mathrm{Pi}\right) / 1000, \mathrm{i}=1,2, \ldots, 8
$$

where:

$P x$ : the final evaluation of variable $\mathrm{x}$; and

$i$ : corresponds to each of the eight respondents.

In order to minimize the cost of the experiment even further, it was decided to limit the number of variables that would meet the Pareto ratio (DIETER, 1999), calculated through the final evaluation score $(P x)$. The five variables chosen as the factors of the experiment are listed in Table 2.

Yet another criterion was devised for choosing the candidate variables to be tested - the simplicity of changing the variable value in order to improve the riveting process. For instance, to change the material of the rivet is easier than to change the riveting process from manual to automatic.

To minimize the cost and the time of the experiment, two levels for each factor were specified, using the existing variations in aeronautical manufacture, as shown in Table 2.

\subsection{Accomplishment of the experiment}

The second stage of the work consisted of measuring several specimens. These specimens were designed and manufactured by using the combinations of all the elected factors based upon the concepts of Design (or delineation) of Experiments and the Taguchi Orthogonal Arrangements (TAGUCHI, 1986). According to Logothetis (1989), three conditions must be satisfied for the execution of Design of Experiments: balance, estimate and orthogonal. It was verified that the five factors met the orthogonal requirement, as they can be set separate and independently. Likewise, all the factors can have its effects estimated; thus the estimate requirement was also met. Then it was necessary to have a detailed plan of experiments in which all the factors would be varied at the same frequency randomly. Each combination of factors would have to be tested in the same amount of experiments, in order to meet the balance requirement.

Table 1. Variables evaluation matrix.

\begin{tabular}{|c|c|c|c|c|c|c|c|c|c|c|c|}
\hline \multirow{2}{*}{$\begin{array}{c}\text { Number of } \\
\text { variable }\end{array}$} & \multirow[t]{2}{*}{ Variables } & \multirow[t]{2}{*}{ PtV/PsV } & \multicolumn{8}{|c|}{ Evaluators score } & \multirow[t]{2}{*}{$P x$} \\
\hline & & & 1 & 2 & 3 & 4 & 5 & 6 & 7 & 8 & \\
\hline 1 & Rivet material & $\mathrm{PtV}$ & 8 & 8 & 8 & 8 & 8 & 8 & 4 & 4 & 524.29 \\
\hline 2 & Thickness of the skin & $\mathrm{PtV}$ & 8 & 4 & 8 & 4 & 4 & 4 & 4 & 4 & 65.54 \\
\hline 3 & Gap before riveting process & $\mathrm{PsV}$ & 8 & 8 & 8 & 8 & 8 & 8 & 8 & 4 & 1048.58 \\
\hline 6 & Riveting sequence & $\mathrm{PsV}$ & 2 & 1 & 4 & 2 & 2 & 2 & 1 & 4 & 0.13 \\
\hline 7 & Type of riveting process & $\mathrm{PsV}$ & 4 & 4 & 2 & 4 & 4 & 2 & 4 & 8 & 16.38 \\
\hline 10 & Countersunk height & PsV & 2 & 4 & 4 & 2 & 4 & 2 & 4 & 2 & 2.05 \\
\hline 11 & Quantity of cycles (strokes) of stamp machine per hole & PsV & 2 & 4 & 2 & 2 & 4 & 2 & 4 & 2 & 1.02 \\
\hline
\end{tabular}

Table 2. Experiment factors and levels.

\begin{tabular}{|c|c|c|c|c|c|c|}
\hline Factor & Symbol of factor & Levels & Symbol & Description & Value & Unity \\
\hline \multirow[t]{2}{*}{ Rivet material } & \multirow{2}{*}{ A } & -1 & $\mathrm{AD}$ & Alloy Al 2117 & $\mathrm{Al} 2117$ & N/A \\
\hline & & 1 & E & Alloy Al 7050 & $\mathrm{Al} 7050$ & N/A \\
\hline \multirow{2}{*}{$\begin{array}{l}\text { Thickness } \\
\text { of the skin }\end{array}$} & \multirow{2}{*}{ B } & -1 & 50 & \multirow{2}{*}{ Thickness skin } & 0.050 & Inch \\
\hline & & 1 & 80 & & 0.080 & Inch \\
\hline \multirow{2}{*}{$\begin{array}{c}\text { Gap before } \\
\text { riveting process }\end{array}$} & \multirow{2}{*}{$\mathrm{C}$} & -1 & $\mathrm{Fm}$ & Minimum gap & 0.09 & $\mathrm{~mm}$ \\
\hline & & 1 & FM & Maximum gap & 0.24 & $\mathrm{~mm}$ \\
\hline \multirow{2}{*}{$\begin{array}{c}\text { Type of riveting } \\
\text { process }\end{array}$} & \multirow{2}{*}{$\mathrm{D}$} & -1 & $\mathrm{M}$ & Manual & \multirow{2}{*}{ N/A } & \multirow{2}{*}{ N/A } \\
\hline & & 1 & A & Automatic & & \\
\hline \multirow{2}{*}{$\begin{array}{c}\text { Countersunk } \\
\text { height }\end{array}$} & \multirow{2}{*}{ E } & -1 & $\mathrm{Am}$ & Minimum height & Rivet 0.3 & $\mathrm{~mm}$ \\
\hline & & 1 & $\mathrm{AM}$ & Maximum height & Rivet aligned to skin & $\mathrm{mm}$ \\
\hline
\end{tabular}


Based on the amount of factors elected to this experiment, the levels of each factor and the number of samples for each combination, the number of specimen was estimated. Due to the lack of experience with regards to skin deformation caused by riveting process, five replications for each combination were performed.

Table 3 summarizes the results.

To accurately simulate the aircraft fuselage assemblies, the specimen is composed of two plates that emulate the stringer, the skin and the yielded thicknesses with usual assembly values (0.063 inches, 0.050 inches and 0.080 inches, respectively).

The pitch of riveting $(2.5 \mathrm{~cm})$ was chosen as the usual value for aeronautical structures, where the number of holes and rivets were calculated from. Figure 1 shows a schematic drawing of the designed specimen and the Figure 2 shows a picture of real specimen.

To fix the two plates to assemble the specimen, two holes with diameter of $2.5 \mathrm{~mm}$ highlighted in Figure 1 were used for inserting two provisory rivets. These holes and rivets were not considered in the measurement of the expansion of the specimen.

To obtain the required precision for aeronautical application, the measurement was performed with a dial gauge, whose accuracy is hundredths of millimeters. As illustrated in Figure 3, the probe measures the length of the specimen in relation to the zero point calibration; the larger is the expansion of specimen and the lower the value measured by the probe. The drawing of the measurement tooling is shown in Figure 3.

The initial and final values of the specimen correspond to the length values read before and after the riveting process. The difference between these values is calculated by Equation 2:

$$
\mathrm{y}=\mathrm{Li}-\mathrm{Lf}
$$

where,

$L f:$ measurement of the specimen length after riveting $(\mathrm{mm})$; $L i$ : measurement of the specimen length before riveting (mm).

To estimate the measurement uncertainty, two main sources were considered: the uncertainty of the dial gauge and the thermal expansion of the plate as presented in Equation 3.

$$
\mathrm{eT}=\mathrm{er}+\mathrm{dtAl}
$$

where,

$e T$ : total measurement uncertainty [mm]

$e r=$ uncertainty of dial gauge $=0.005 \mathrm{~mm}$ according to its technical data sheet.

$d t A l$ : linear thermal expansion of aluminum [mm], calculated by Equation 4 as Callister (2006) and Van Vlack (1989):

$$
\mathrm{dtAl}=\mathrm{Lo} * \mathrm{ct} * \Delta \mathrm{t}
$$

Table 3. Sample Size of the experiment.

\begin{tabular}{|l|r|}
\hline Number of levels per factor & 2 \\
\hline Number of variables & 5 \\
\hline Number of combinations & 32 \\
\hline Number of replications & 5 \\
\hline Number of specimen & 160 \\
\hline
\end{tabular}

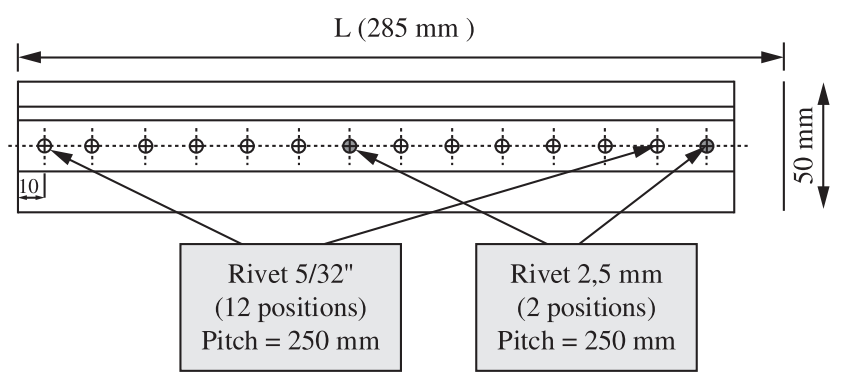

Figure 1. Drawing of specimen.

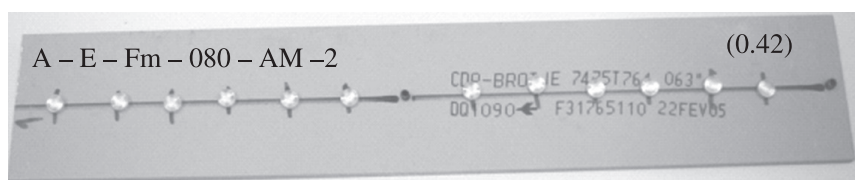

Figure 2. Real specimen photo.

where,

$c t$ : thermal expansion coefficient of aluminum $\left[{ }^{\circ} \mathrm{C}^{-1}\right]$

$\mathrm{D} t$ : variation of temperature $\left[{ }^{\circ} \mathrm{C}\right]$ and

$L o$ : initial length of the specimen $(285 \mathrm{~mm})$.

In a controlled environment with maximum temperature variation of $1{ }^{\circ} \mathrm{C}$ e ct $=23.8 .10 \mathrm{E}-6 /{ }^{\circ} \mathrm{C}(\mathrm{MATWEB}$ MATERIAL PROPERTY DATA, 2008), Equations 4 and 3 yields, respectively:

$$
\begin{aligned}
& \mathrm{dtAl}=285 * 23.8 .10^{-6} * 1=0.006783[\mathrm{~mm}] \\
& \mathrm{eT}=\mathrm{er}+\mathrm{dtAl}=0.005+0.006783 \approx 0.01[\mathrm{~mm}]
\end{aligned}
$$

\section{Analysis of data}

The analysis of the results of the experiment was based upon the concepts of Total Factorial Design with five replications (MONTGOMERY, 2001).

Analysis of Variance - ANAVA (DEVORE, 2004) were used to analyze the resulting data from the experiments. For this work, this analysis was performed using the software Minitab $^{\mathrm{TM}}$ version 15 (MINITAB, 2008).

The data collected from experiment is shown in the Appendix.

\subsection{Identification of significant factors}

This was carried out by analysing two sources, namely Normal Probability Plot of Effects (item 3.1.1) and Residual Analysis of Fit Linear Model (item 3.1.2). 


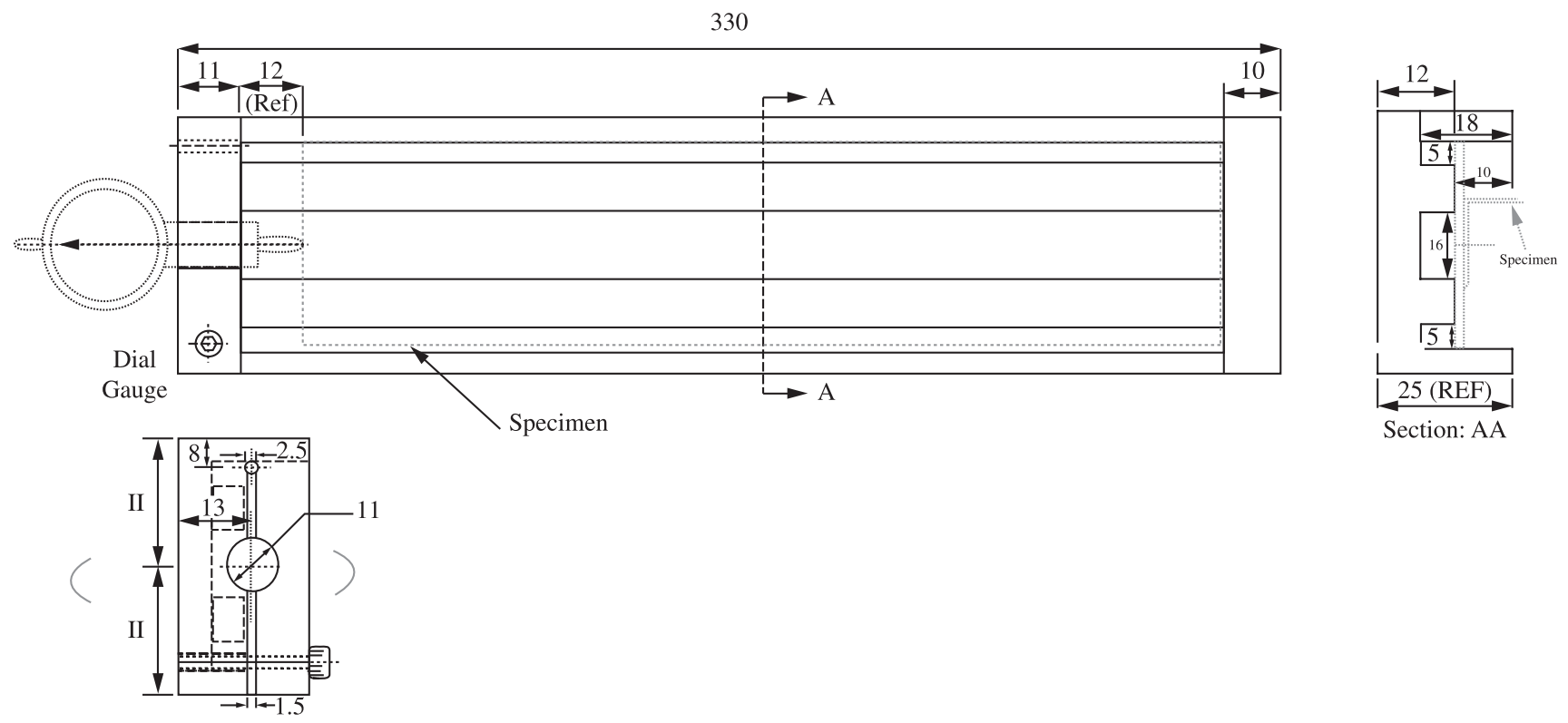

Figure 3. Drawing of the measurement tooling [mm].

\subsubsection{Normal probability plot of effects}

Figure 4 presents the Normal Probability Plot of the Effects results of the ANAVA for Total Factorial Design with five replications.

In a decreasing sequence of significance, the significant factors or combination of them are: D - Thickness of skin, B - Rivet material, and E - Countersunk height, $\mathrm{AB}$ - Combination between Riveting process and Rivet material, A - Riveting process, AD - Combination between Riveting process and Thickness of the skin, $\mathrm{ABCE}$ - Combination among Riveting process, Rivet material, Gap before the riveting process and Countersunk height, BCE - Combination among Gap before the Riveting process, Rivet material and Countersunk height, CDE - Combination among Gap before the riveting process, Thickness of the skin and Countersunk height, $\mathrm{AE}$-Combination among Riveting process and Countersunk height and $\mathrm{AC}$ - Combination between Riveting process and Gap before the riveting process.

Figure 5 presents the Pareto Chart of the Standardized Effects for Total Factorial Design with five replications and ratifies the results presented in Figure 4.

The critical value $t$ determines the limit to reject the null hypothesis, i.e. the factor analyzed is significant. This critical value $t$ is obtained from $t$ Distribution (freedom degree $\mathrm{n}=128$, significance level $\mathrm{a}=0,05)$ (DEVORE, 2004).

It can be noticed from Figures 4 and 5 that the factors or their combinations which are far from the normal curve are those whose Standardized Effect values are greater than the critical value $t=1,979$, i.e. they are significant.

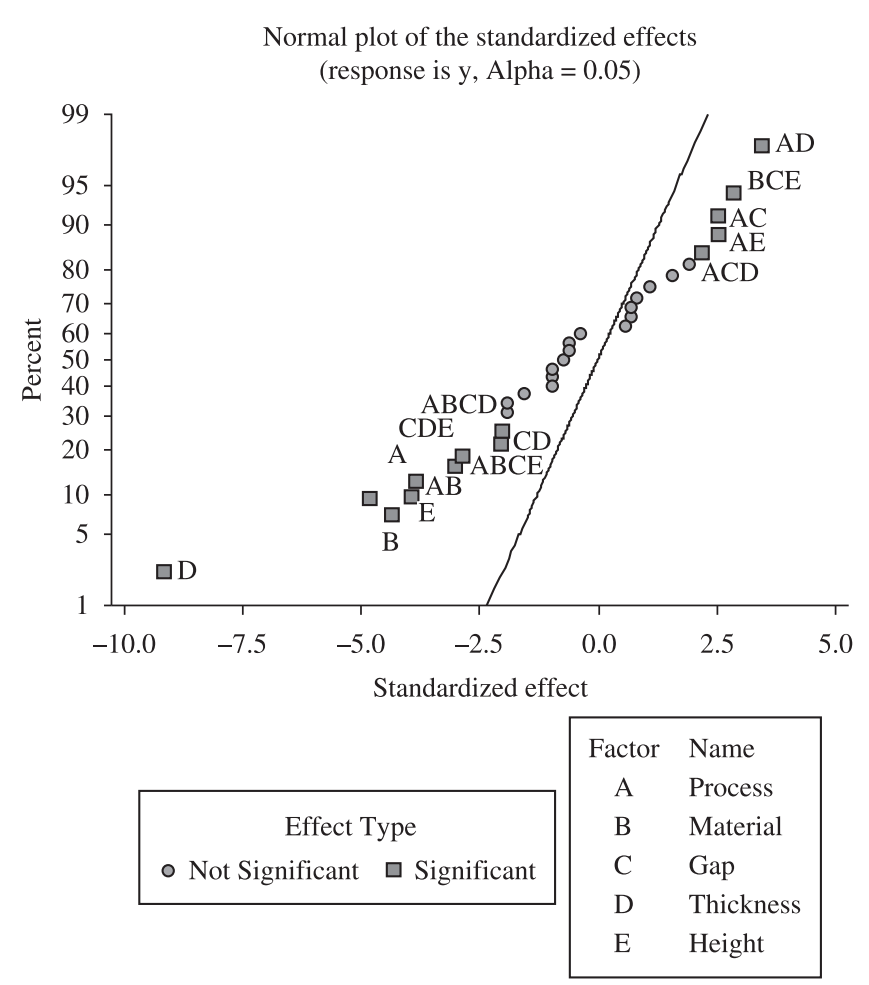

Figure 4. Normal probability of effects.

\subsubsection{Residual analysis of fit linear model: $y$}

The reliability of the fit linear model used to estimate the response curve y can be verified by analyzing the Residual Graphs: Normal Probability Plot, Histogram, Residuals versus Fitted value and Residuals versus order. 


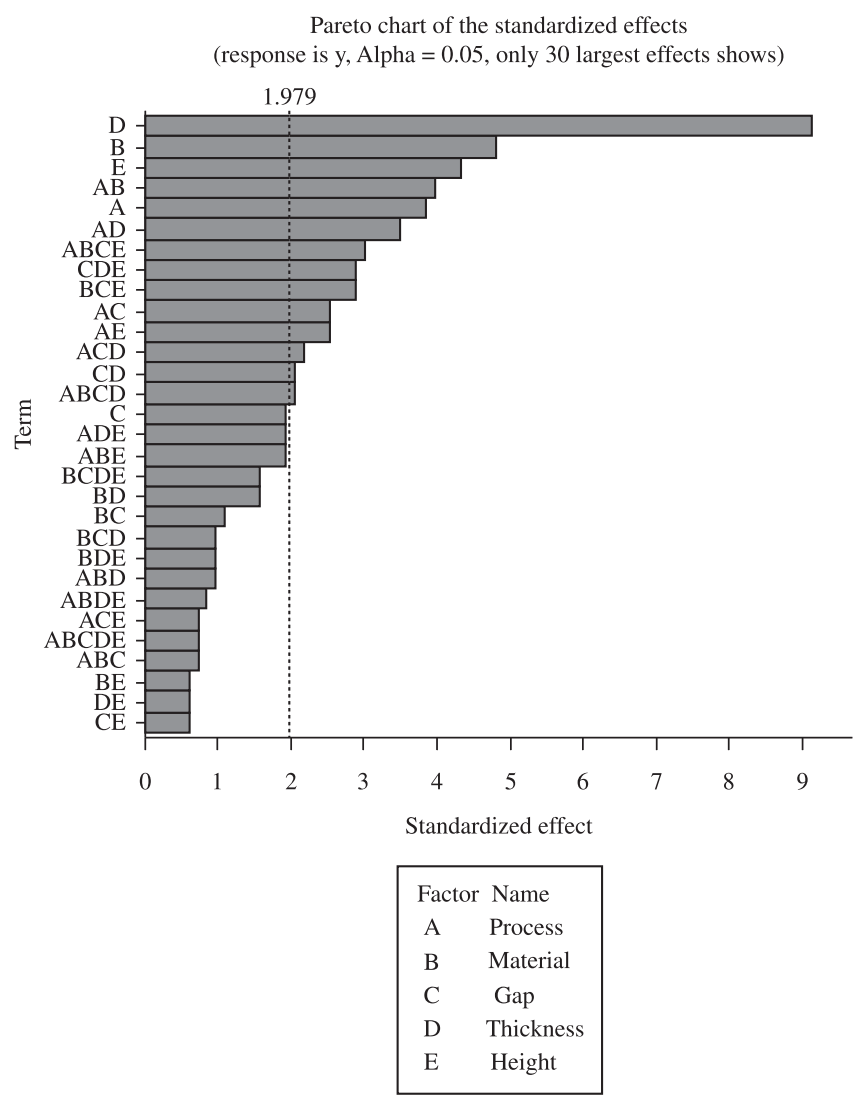

This analysis is illustrated in Figure 6.

It can be noticed from Figure 6 that almost all residual plots present a normal behavior (close to normal line in Normal Probability Plot, normal curve in Histogram and no trend in Residual versus Observation Order). But in the Residual versus Fitted Value Plot, there is a trend indicating that there might be other significant factors and/or combinations that influence the response $y$, and consequently the deformation in aluminum alloy caused by riveting process.

\subsection{Interaction analysis}

If the interaction is present between two or more factors, the actions to minimize the response y, should be applied in both factors simultaneously.

It is clear that the most significant factor by far is the D-Thickness of skin, but there are significant combinations with this factor, so it is worth analyzing the interaction of all factors within each combination before validating the main significance of factor.

Figure 7 shows the interaction plots of the response $y$ for all factors and combinations.

Figure 7 shows that the significant pairs of factors, identified in Identification of Significant Factors (item 3.1.), that present high interaction are: $\mathrm{AB}$ - Process and Material,

Figure 5. Pareto chart of the standardized effects.

Residual plots for $\mathrm{y}$

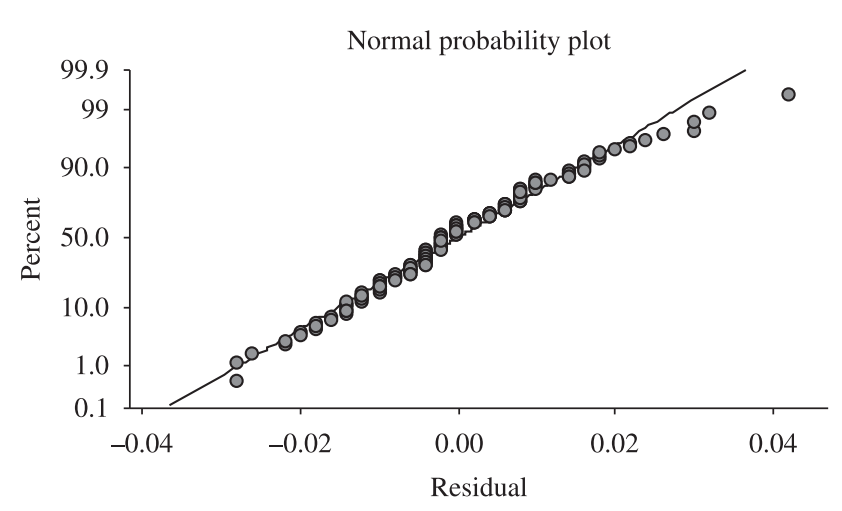

Histogram

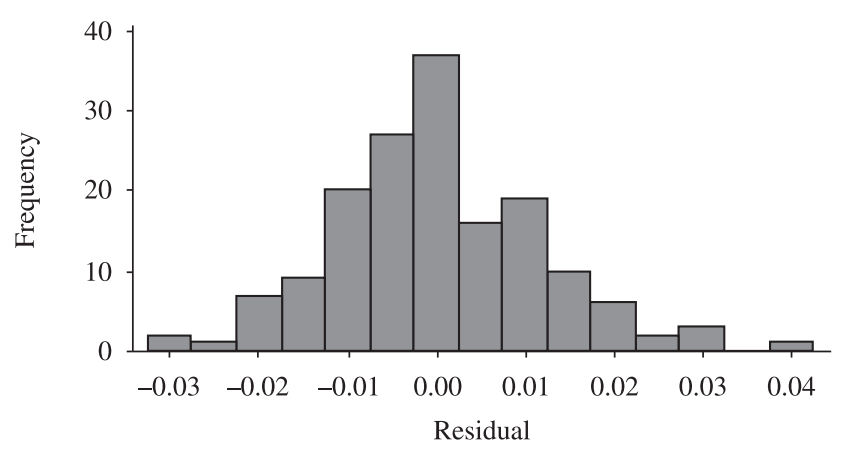

Versus fits
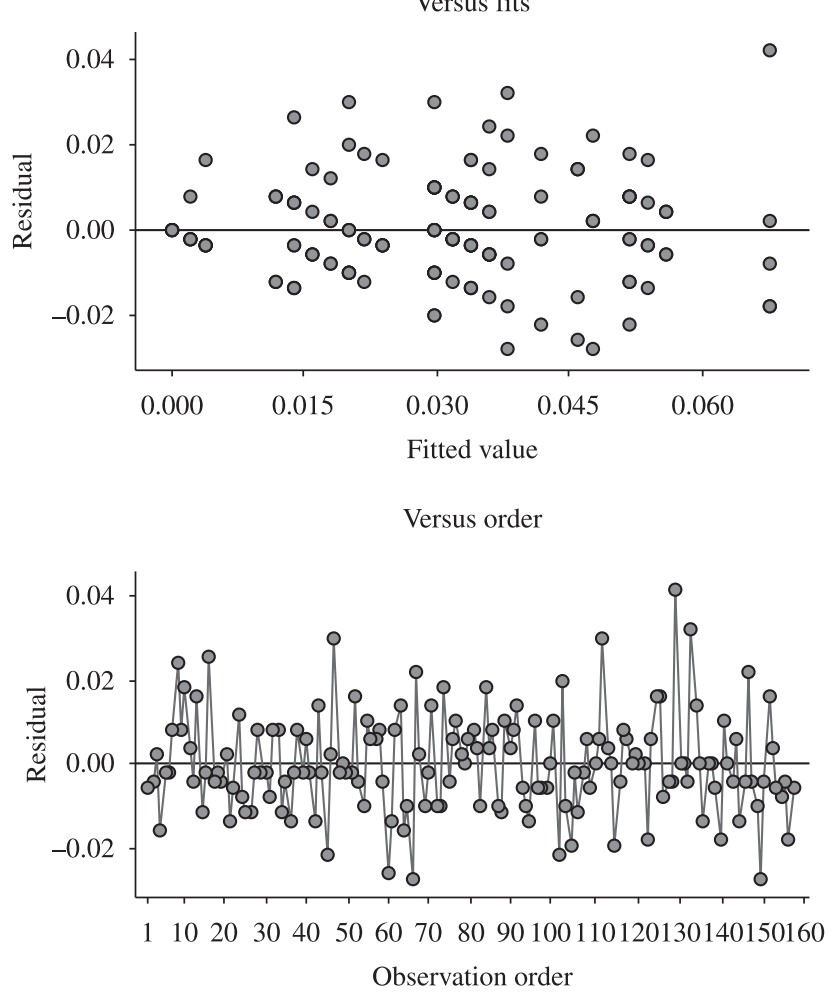

Figure 6. Residual plots for y. 
AC - Process and Gap, AD - Process and Thickness, AE - Process and Height and CD - Gap and Thickness.

As all of the five factors present interaction with some other factor, the individual analysis of each factor is not valid. Consequently, all factors must be analyzed considering its interaction and the actions in the process must be taken in all factors, simultaneously.

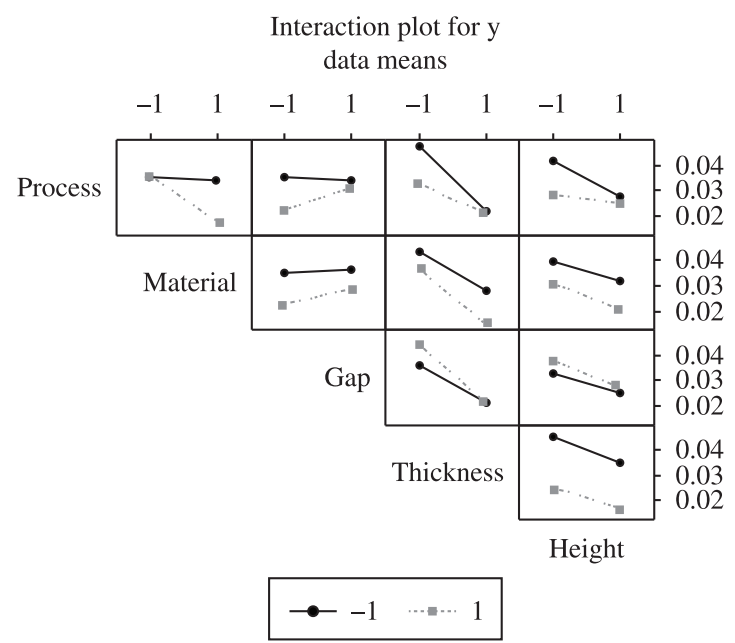

Figure 7. Interaction plot for $\mathrm{y}$.

\section{Conclusions}

The experiments described herein analyzed the effect of deformation in aluminum alloy skin, when applied to a determined riveting process. They identified, among the factors selected - diameter of the hole, height of countersunk, material of the rivet, thickness of the skin and type of riveting, manual or automatic - those most influence the deformation of the skin, as well as the degree of this influence.

This is summarized in Tables 4 and 5 .

Tables 4 and 5 present the summary of the analysis, its respective significant factors and its levels of the lowest data mean value of $y$. It can be concluded that all actions listed above can reduce the deformation in skin caused by riveting process, but the deformation is minimized if all actions are applied simultaneously due to the interaction among all factors. Action 1 is more viable to implant in Product Design Phase and the actions 2, 3 and 4 during Product Manufacturing Phase.

The biggest deformation observed in the riveting process was $0.11 \mathrm{~mm}$ (Appendix, Table 6, number of sample: 131). Considering an aircraft panel with riveting lines of 150 rivets, this would represent a linear expansion of $0.9 \mathrm{~mm}$. As this expansion occurs in the riveting line, it induces warping and twisting in the panels, modifying the

Table 4. Results of analysis.

\begin{tabular}{|c|c|c|}
\hline Significant factors $\alpha=\mathbf{0 , 0 5}$ & Significant pairs & Interaction? \\
\hline D - Thickness & AB - Process and material & Yes \\
\hline B - Material & AC - Process and gap & Yes \\
\hline E - Height & AD - Process and thickness & Yes \\
\hline AB - Process and material & AE - Process and height & No \\
\hline A - Process & BC - Material and gap & Yes \\
\hline AD - Process and thickness & BE - Material and height & No \\
\hline ABCE - Process, material, gap and height & CD - Gap and thickness & No \\
\hline BCE - Gap, material and height & CE - Gap and height & - \\
\hline CDE - Gap, thickness and height & DE - Thickness and height & - \\
\hline AE - Process and height & - & \\
\hline AC - Process and gap & - & \\
\hline
\end{tabular}

Table 5. Results of analysis and prescribed actions.

\begin{tabular}{|c|l|l|}
\hline $\begin{array}{c}\text { Significant factor } \\
\text { with interaction }\end{array}$ & \multicolumn{1}{|c|}{$\begin{array}{c}\text { Level of the lowest } \\
\text { data mean of }(\mathbf{y})\end{array}$} & $\begin{array}{c}\text { Possible actions to reduce } \\
\text { the deformation }(\mathbf{y})\end{array}$ \\
\hline & Process (1): Automatic & $\begin{array}{l}\text { 1. To project thickness skin bigger than 0.080 inch and Rivet Material E in } \\
\text { junction regions of fuselage; }\end{array}$ \\
$\begin{array}{c}\text { ABCDE - Process, } \\
\text { material, gap, thickness } \\
\text { and height }\end{array}$ & $\begin{array}{l}\text { Gap (-1): Minimum } \\
\text { Thickness (1): } 0,080 \text { inch } \\
\text { Height (1): Maximum }\end{array}$ & $\begin{array}{l}\text { 3. To setup automatic riveting process; } \\
\text { 4. To setup the drill tool for minimum diameter hole to produce minimum } \\
\text { gap. (E.g. to use new drill tool). }\end{array}$ \\
\hline
\end{tabular}


designed riveting line. Through a geometric calculation, the expansion of $1 \mathrm{~mm}$ would approximately cause deformation - in the aerodynamic system line of a panel with 150 rivets - up to $2.4 \mathrm{~cm}$.

\subsection{Possible alternatives to reduce the deformation effect}

Besides the actions presented in Table 5, further actions which are not directly related to the factors might be considered for both, process and product. Naturally the implementation of the suggestions presented below, depend of further functional and financial analysis:

- To project a tooling to eliminate or minimize the stretching and the warping of the skin;

- To project machined caves to guarantee the system line avoiding the deformation of the skin.

\subsection{Future developments}

Several opportunities for future developments of this work are listed below.

- The measurements of panels structures to be made through photogrammetry or laser tracking (LEICA GEOSYSTEMS, 2011). With these devices it is possible to obtain the linear measurement of the specimen, as well as the alteration in the line of system. A curve of the product manufactured in relation to the projected curve in axes $\mathrm{x}, \mathrm{y}$ and $\mathrm{z}$.

- To conduct experiments with other types of fasteners used in the aeronautical industry that such as: HI-LOK, HI-LITE, LOCK-BOLT (ALCOA, 2006) as well as other diameters of holes used with the Brille rivet or solid.

- To analyze the effect of other factors namely the

Surface plot of y vs material, process
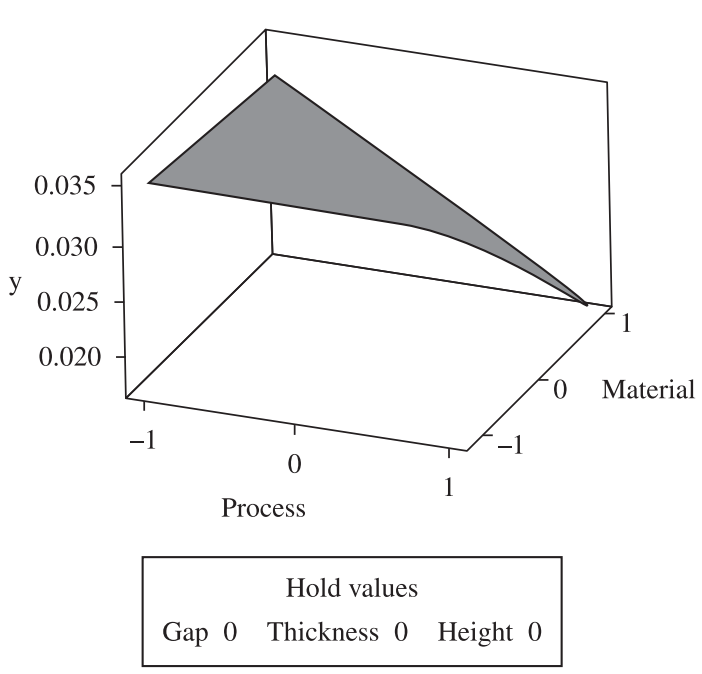

Figure 8. Surface plot y versus material and process. riveting sequence and the direction of the material grain of the plate, because the Residual versus Fitted value Plot presented a trend confirming the existence of other relevant factors.

- To create simulation models of this phenomenon, using finite element application software like MARC $^{\mathrm{TM}}$ (LI; SHI, 2003) for previous analysis during the Product Development Phase, avoiding non-conformities of product in its following phases, as shown in Figure 8 in Surface Plot of y versus Material and Process.

\section{References}

ALCOA. Alcoa Fastening Systems Aerospace. Disponível em: $<$ http://www.alcoa.com/fastening_systems/aerospace/en/ market_category.asp?cat_id=671 >. Acesso em: 5 ago 2011.

AMERICAN NATIONAL STANDARDS INSTITUTE - ANSI. NASM 14219: Rivet, solid, 120 deg. flush interference, tension type head. New York: ANSI, 1999.

BLANCHOT, V.; DAIDIE, A. Riveted assembly modelling: Study and numerical characterisation of a Riveting process. Journal of Materials Processing Technology, v. 180, n. 1-3, p. 201-209, 2006. http://dx.doi.org/10.1016/j. jmatprotec.2006.06.005

CALLISTER, W. D. Materials Science and Engineering: An Introduction. 7th ed. Hoboken: John Wiley \& Sons, 2006.

DEVORE, J. L. Probability and Statistics for Engineering and the Sciences. South Bank: Thomson, 2004.

DIETER, G. E. Engineering Design: A Materials and Processing Approach. 3th ed. New York: McGrawHill, 1999.

JOHNSON, T. J. et al. Diagnostics of tool-part interactions during riveting on an aluminum aircraft fuselage. Journal of Aircraft, v. 43, n. 3, p. 779-786, 2006. http://dx.doi. org/10.2514/1.17203

LEICA GEOSYSTEMS. Laser Tracker Systems. Disponível em: <http://www.leica-geosystems.us/en/Laser-TrackerSystems_69045.htm>. Acesso em: 5 ago 2011.

LI, G.; SHI, H. Effect of Riveting process on the residual stress in fuselage Lap Joints. Canadian Aeronautics and Space Journal, v. 50, n. 2, p. 91-105, 2004. http://dx.doi. org/10.5589/q04-007

LOGOTHETIS, N. Quality through design: experimental design, off-line quality control and Taguchi's contributions. Oxford: Clarendon Press, 1989.

MATWEB MATERIAL PROPERTY DATA. Property search. Disponível em: <http://www.matweb.com/search/ SearchProperty.asp>. Acesso em: 5 ago 2011. 
MINITAB. Minitab 16. Disponível em: <http://www.minitab. com/products/minitab/>. Acesso em: 5 ago 2011.

MONTGOMERY, D. C. Design and analysis of experiments. 5th ed. Hoboken: John Wiley \& Sons, 2001.

RANS, C.; STRAZNICKY, P. V.; ALDERLIESTEN, R. Riveting process induced residual stresses around solid rivets in mechanical joints. Journal of Aircraft, v. 44, n. 1, p. 323-329, 2007. http://dx.doi.org/10.2514/1.23684
TAGUCHI, G. Introduction to quality engineering: designing quality into products and processes. Tokyo: Asian Productivity Organization, 1986.

VAN VLACK, L. H. Elements of material science and engineering. 6th ed. Reading: A: Addison-Wesley, 1989.

\section{APPENDIX}

The data bellow is the output of the experiment, that is, the deformation in aluminum alloy skin caused by riveting process $[\mathrm{mm}]$.

Table 6 shows the data obtained from the experiment.

Note: The zero values in the table refer to the specimen with excessive warp due to deformation caused by riveting process.

Table 6. Experiment data.

\begin{tabular}{|c|c|c|c|c|c|c|}
\hline & Process & Material & Gap & Thickness & Height & $\mathbf{y}$ \\
\hline 1 & -1 & -1 & -1 & -1 & -1 & 0.03 \\
\hline 2 & -1 & -1 & -1 & -1 & -1 & 0.00 \\
\hline 3 & -1 & -1 & -1 & -1 & -1 & 0.02 \\
\hline 4 & -1 & -1 & -1 & -1 & -1 & 0.02 \\
\hline 5 & -1 & -1 & -1 & -1 & -1 & 0.02 \\
\hline 6 & -1 & -1 & -1 & -1 & 1 & 0.03 \\
\hline 7 & -1 & -1 & -1 & -1 & 1 & 0.02 \\
\hline 8 & -1 & -1 & -1 & -1 & 1 & 0.06 \\
\hline 9 & -1 & -1 & -1 & -1 & 1 & 0.02 \\
\hline 10 & -1 & -1 & -1 & -1 & 1 & 0.04 \\
\hline 11 & -1 & -1 & -1 & 1 & -1 & 0.04 \\
\hline 12 & -1 & -1 & -1 & 1 & -1 & 0.00 \\
\hline 13 & -1 & -1 & -1 & 1 & -1 & 0.02 \\
\hline 14 & -1 & -1 & -1 & 1 & -1 & 0.00 \\
\hline 15 & -1 & -1 & -1 & 1 & -1 & 0.00 \\
\hline 16 & -1 & -1 & -1 & 1 & 1 & 0.04 \\
\hline 17 & -1 & -1 & -1 & 1 & 1 & 0.00 \\
\hline 18 & -1 & -1 & -1 & 1 & 1 & 0.02 \\
\hline 19 & -1 & -1 & -1 & 1 & 1 & 0.00 \\
\hline 20 & -1 & -1 & -1 & 1 & 1 & 0.02 \\
\hline 21 & -1 & -1 & 1 & -1 & -1 & 0.00 \\
\hline 22 & -1 & -1 & 1 & -1 & -1 & 0.03 \\
\hline 23 & -1 & -1 & 1 & -1 & -1 & 0.03 \\
\hline 24 & -1 & -1 & 1 & -1 & -1 & 0.01 \\
\hline 25 & -1 & -1 & 1 & -1 & -1 & 0.00 \\
\hline 26 & -1 & -1 & 1 & -1 & 1 & 0.02 \\
\hline 27 & -1 & -1 & 1 & -1 & 1 & 0.03 \\
\hline 28 & -1 & -1 & 1 & -1 & 1 & 0.04 \\
\hline 29 & -1 & -1 & 1 & -1 & 1 & 0.00 \\
\hline 30 & -1 & -1 & 1 & -1 & 1 & 0.02 \\
\hline 31 & -1 & -1 & 1 & 1 & -1 & 0.01 \\
\hline
\end{tabular}


Table 6. Continued...

\begin{tabular}{|c|c|c|c|c|c|c|}
\hline & Process & Material & Gap & Thickness & Height & $\mathbf{y}$ \\
\hline 32 & -1 & -1 & 1 & 1 & -1 & 0.01 \\
\hline 33 & -1 & -1 & 1 & 1 & -1 & 0.02 \\
\hline 34 & -1 & -1 & 1 & 1 & -1 & 0.01 \\
\hline 35 & -1 & -1 & 1 & 1 & -1 & 0.01 \\
\hline 36 & -1 & -1 & 1 & 1 & 1 & 0.00 \\
\hline 37 & -1 & -1 & 1 & 1 & 1 & 0.00 \\
\hline 38 & -1 & -1 & 1 & 1 & 1 & 0.04 \\
\hline 39 & -1 & -1 & 1 & 1 & 1 & 0.00 \\
\hline 40 & -1 & -1 & 1 & 1 & 1 & 0.02 \\
\hline 41 & -1 & 1 & -1 & -1 & -1 & 0.03 \\
\hline 42 & -1 & 1 & -1 & -1 & -1 & 0.02 \\
\hline 43 & -1 & 1 & -1 & -1 & -1 & 0.06 \\
\hline 44 & -1 & 1 & -1 & -1 & -1 & 0.03 \\
\hline 45 & -1 & 1 & -1 & -1 & -1 & 0.02 \\
\hline 46 & -1 & 1 & -1 & -1 & 1 & 0.05 \\
\hline 47 & -1 & 1 & -1 & -1 & 1 & 0.05 \\
\hline 48 & -1 & 1 & -1 & -1 & 1 & 0.03 \\
\hline 49 & -1 & 1 & -1 & -1 & 1 & 0.02 \\
\hline 50 & -1 & 1 & -1 & -1 & 1 & 0.04 \\
\hline 51 & -1 & 1 & -1 & 1 & -1 & 0.03 \\
\hline 52 & -1 & 1 & -1 & 1 & -1 & 0.05 \\
\hline 53 & -1 & 1 & -1 & 1 & -1 & 0.03 \\
\hline 54 & -1 & 1 & -1 & 1 & -1 & 0.01 \\
\hline 55 & -1 & 1 & -1 & 1 & -1 & 0.04 \\
\hline 56 & -1 & 1 & -1 & 1 & 1 & 0.04 \\
\hline 57 & -1 & 1 & -1 & 1 & 1 & 0.04 \\
\hline 58 & -1 & 1 & -1 & 1 & 1 & 0.05 \\
\hline 59 & -1 & 1 & -1 & 1 & 1 & 0.03 \\
\hline 60 & -1 & 1 & -1 & 1 & 1 & 0.02 \\
\hline 61 & -1 & 1 & 1 & -1 & -1 & 0.02 \\
\hline 62 & -1 & 1 & 1 & -1 & -1 & 0.04 \\
\hline 63 & -1 & 1 & 1 & -1 & -1 & 0.06 \\
\hline 64 & -1 & 1 & 1 & -1 & -1 & 0.03 \\
\hline 65 & -1 & 1 & 1 & -1 & -1 & 0.01 \\
\hline 66 & -1 & 1 & 1 & -1 & 1 & 0.02 \\
\hline 67 & -1 & 1 & 1 & -1 & 1 & 0.07 \\
\hline 68 & -1 & 1 & 1 & -1 & 1 & 0.05 \\
\hline 69 & -1 & 1 & 1 & -1 & 1 & 0.02 \\
\hline 70 & -1 & 1 & 1 & -1 & 1 & 0.04 \\
\hline 71 & -1 & 1 & 1 & 1 & -1 & 0.06 \\
\hline 72 & -1 & 1 & 1 & 1 & -1 & 0.02 \\
\hline 73 & -1 & 1 & 1 & 1 & -1 & 0.01 \\
\hline 74 & -1 & 1 & 1 & 1 & -1 & 0.06 \\
\hline 75 & -1 & 1 & 1 & 1 & -1 & 0.03 \\
\hline 76 & -1 & 1 & 1 & 1 & 1 & 0.04 \\
\hline 77 & -1 & 1 & 1 & 1 & 1 & 0.04 \\
\hline 78 & -1 & 1 & 1 & 1 & 1 & 0.05 \\
\hline 79 & -1 & 1 & 1 & 1 & 1 & 0.03 \\
\hline 80 & -1 & 1 & 1 & 1 & 1 & 0.04 \\
\hline 81 & 1 & -1 & -1 & -1 & -1 & 0.06 \\
\hline
\end{tabular}


Table 6. Continued...

\begin{tabular}{|c|c|c|c|c|c|c|}
\hline & Process & Material & Gap & Thickness & Height & $\mathbf{y}$ \\
\hline 82 & 1 & -1 & -1 & -1 & -1 & 0.02 \\
\hline 83 & 1 & -1 & -1 & -1 & -1 & 0.01 \\
\hline 84 & 1 & -1 & -1 & -1 & -1 & 0.07 \\
\hline 85 & 1 & -1 & -1 & -1 & -1 & 0.06 \\
\hline 86 & 1 & -1 & -1 & -1 & 1 & 0.06 \\
\hline 87 & 1 & -1 & -1 & -1 & 1 & 0.02 \\
\hline 88 & 1 & -1 & -1 & -1 & 1 & 0.04 \\
\hline 89 & 1 & -1 & -1 & -1 & 1 & 0.04 \\
\hline 90 & 1 & -1 & -1 & -1 & 1 & 0.06 \\
\hline 91 & 1 & -1 & -1 & 1 & -1 & 0.06 \\
\hline 92 & 1 & -1 & -1 & 1 & -1 & 0.03 \\
\hline 93 & 1 & -1 & -1 & 1 & -1 & 0.01 \\
\hline 94 & 1 & -1 & -1 & 1 & -1 & 0.02 \\
\hline 95 & 1 & -1 & -1 & 1 & -1 & 0.00 \\
\hline 96 & 1 & -1 & -1 & 1 & 1 & 0.04 \\
\hline 97 & 1 & -1 & -1 & 1 & 1 & 0.01 \\
\hline 98 & 1 & -1 & -1 & 1 & 1 & 0.05 \\
\hline 99 & 1 & -1 & -1 & 1 & 1 & 0.01 \\
\hline 100 & 1 & -1 & -1 & 1 & 1 & 0.02 \\
\hline 101 & 1 & -1 & 1 & -1 & -1 & 0.04 \\
\hline 102 & 1 & -1 & 1 & -1 & -1 & 0.03 \\
\hline 103 & 1 & -1 & 1 & -1 & -1 & 0.04 \\
\hline 104 & 1 & -1 & 1 & -1 & -1 & 0.01 \\
\hline 105 & 1 & -1 & 1 & -1 & -1 & 0.01 \\
\hline 106 & 1 & -1 & 1 & -1 & 1 & 0.05 \\
\hline 107 & 1 & -1 & 1 & -1 & 1 & 0.04 \\
\hline 108 & 1 & -1 & 1 & -1 & 1 & 0.05 \\
\hline 109 & 1 & -1 & 1 & -1 & 1 & 0.02 \\
\hline 110 & 1 & -1 & 1 & -1 & 1 & 0.05 \\
\hline 111 & 1 & -1 & 1 & 1 & -1 & 0.02 \\
\hline 112 & 1 & -1 & 1 & 1 & -1 & 0.02 \\
\hline 113 & 1 & -1 & 1 & 1 & -1 & 0.06 \\
\hline 114 & 1 & -1 & 1 & 1 & -1 & 0.06 \\
\hline 115 & 1 & -1 & 1 & 1 & -1 & 0.03 \\
\hline 116 & 1 & -1 & 1 & 1 & 1 & 0.01 \\
\hline 117 & 1 & -1 & 1 & 1 & 1 & 0.01 \\
\hline 118 & 1 & -1 & 1 & 1 & 1 & 0.06 \\
\hline 119 & 1 & -1 & 1 & 1 & 1 & 0.02 \\
\hline 120 & 1 & -1 & 1 & 1 & 1 & 0.03 \\
\hline 121 & 1 & 1 & -1 & -1 & -1 & 0.07 \\
\hline 122 & 1 & 1 & -1 & -1 & -1 & 0.00 \\
\hline 123 & 1 & 1 & -1 & -1 & -1 & 0.03 \\
\hline 124 & 1 & 1 & -1 & -1 & -1 & 0.05 \\
\hline 125 & 1 & 1 & -1 & -1 & -1 & 0.06 \\
\hline 126 & 1 & 1 & -1 & -1 & 1 & 0.05 \\
\hline 127 & 1 & 1 & -1 & -1 & 1 & 0.04 \\
\hline 128 & 1 & 1 & -1 & -1 & 1 & 0.06 \\
\hline 129 & 1 & 1 & -1 & -1 & 1 & 0.02 \\
\hline 130 & 1 & 1 & -1 & -1 & 1 & 0.05 \\
\hline 131 & 1 & 1 & -1 & 1 & -1 & 0.11 \\
\hline
\end{tabular}


Table 6. Continued...

\begin{tabular}{|c|c|c|c|c|c|c|}
\hline & Process & Material & Gap & Thickness & Height & $\mathbf{y}$ \\
\hline 132 & 1 & 1 & -1 & 1 & -1 & 0.00 \\
\hline 133 & 1 & 1 & -1 & 1 & -1 & 0.00 \\
\hline 134 & 1 & 1 & -1 & 1 & -1 & 0.02 \\
\hline 135 & 1 & 1 & -1 & 1 & -1 & 0.07 \\
\hline 136 & 1 & 1 & -1 & 1 & 1 & 0.05 \\
\hline 137 & 1 & 1 & -1 & 1 & 1 & 0.00 \\
\hline 138 & 1 & 1 & -1 & 1 & 1 & 0.04 \\
\hline 139 & 1 & 1 & -1 & 1 & 1 & 0.00 \\
\hline 140 & 1 & 1 & -1 & 1 & 1 & 0.03 \\
\hline 141 & 1 & 1 & 1 & -1 & -1 & 0.03 \\
\hline 142 & 1 & 1 & 1 & -1 & -1 & 0.05 \\
\hline 143 & 1 & 1 & 1 & -1 & -1 & 0.04 \\
\hline 144 & 1 & 1 & 1 & -1 & -1 & 0.03 \\
\hline 145 & 1 & 1 & 1 & -1 & -1 & 0.02 \\
\hline 146 & 1 & 1 & 1 & -1 & 1 & 0.04 \\
\hline 147 & 1 & 1 & 1 & -1 & 1 & 0.02 \\
\hline 148 & 1 & 1 & 1 & -1 & 1 & 0.03 \\
\hline 149 & 1 & 1 & 1 & -1 & 1 & 0.06 \\
\hline 150 & 1 & 1 & 1 & -1 & 1 & 0.05 \\
\hline 151 & 1 & 1 & 1 & 1 & -1 & 0.02 \\
\hline 152 & 1 & 1 & 1 & 1 & -1 & 0.01 \\
\hline 153 & 1 & 1 & 1 & 1 & -1 & 0.02 \\
\hline 154 & 1 & 1 & 1 & 1 & -1 & 0.07 \\
\hline 155 & 1 & 1 & 1 & 1 & -1 & 0.04 \\
\hline 156 & 1 & 1 & 1 & 1 & 1 & 0.03 \\
\hline 157 & 1 & 1 & 1 & 1 & 1 & 0.03 \\
\hline 158 & 1 & 1 & 1 & 1 & 1 & 0.03 \\
\hline 159 & 1 & 1 & 1 & 1 & 1 & 0.02 \\
\hline 160 & 1 & 1 & 1 & 1 & 1 & 0.03 \\
\hline
\end{tabular}

